\title{
Undernutrition among Pregnant Women in Rural Communities in Southern Ethiopia
}

This article was published in the following Dove Press journal:

International Journal of Women's Health

\author{
Solomon Zewdie' \\ Sagni Girma Fage $\mathbb{1 D}^{2}$ \\ Abera Kenay Tura ${ }^{2,3}$ \\ Fitsum Weldegebreal $\mathbb{D}^{4}$ \\ 'Goro Dola Woreda Health Office, Guji \\ Zone, Oromia Regional State, Goro \\ Dola, Ethiopia; ${ }^{2}$ School of Nursing and \\ Midwifery, College of Health and Medical \\ Sciences, Haramaya University, Harar, \\ Ethiopia; ${ }^{3}$ Department of Obstetrics and \\ Gynaecology, University Medical Centre \\ Groningen, University of Groningen, the \\ Netherlands; ${ }^{4}$ College of Health and \\ Medical Sciences, Haramaya University, \\ Harar, Ethiopia
}

Background: Maternal undernutrition rates in Ethiopia are among the highest in the world. In addition, a huge inequity exists within the country, with pregnant women in rural communities being at increased risk. This study assessed the prevalence of undernutrition and its associated factors among pregnant women in a rural community in southern Ethiopia.

Methods: A community-based cross-sectional study was conducted among 376 randomly selected pregnant women. Data were collected through face-to-face interview followed by mid-upper arm circumference measurement. Household food insecurity and minimum dietary diversity for women were assessed. Data were entered into EpiData 3.1 and exported to SPSS 20 for analysis. Logistic regression models were fitted to check associations between independent variables and undernutrition. Statistical significance was set at $p<0.05$.

Results: The prevalence of undernutrition was $41.2 \%$ (95\% CI 36.3\%-46.3\%). Unintended pregnancy (AOR 2.06, 95\% CI 1.27-3.36) and not participating in Wome's Health Development Army meetings (AOR 3.64, 95\% CI 1.51-8.77) were independent predictors of undernutrition. However, minimum dietary diversity for women of five or more food groups (AOR 0.24, 95\% CI 0.07-0.82), having at least one antenatal care visit (AOR 0.46, $95 \%$ CI $0.27-0.78$ ), age at first pregnancy $\geq 20$ years (AOR $0.39,95 \%$ CI $0.21-0.76$ ), and being from food-secure households (AOR 0.26 , 95\% CI $0.16-0.43$ ) were independent protective factors against undernutrition.

Conclusion: Undernutrition among pregnant women was highly prevalent in the study area. Interventions aiming to reduce undernutrition should focus on discouraging teenage and unintended pregnancy, reducing household food insecurity, and promoting antenatal care visits and encouraging consumption of diversified diets by women. Strengthening the existing network of the Women's Health Development Army seems to be very important.

Keywords: undernutrition, pregnant women, rural community, Ethiopia

\section{Introduction}

Malnutrition is where a deficiency or excess of energy, protein, and other nutrients causes measurable adverse effects on tissue or body form (body function and clinical outcome). It is a broad term that includes overnutrition, undernutrition, and malnutrition of micronutrients. ${ }^{1-3}$

Undernutrition denotes insufficient intake of energy and nutrients to meet an individual's needs to maintain good health. ${ }^{4}$ It is a global public health problem contributing directly or indirectly to the death of 3.5 million women annually, mainly in low- and middle-income countries. ${ }^{5-7}$ Children and pregnant and lactating women are among the groups most vulnerable to undernutrition. ${ }^{8,9}$ In addition, maternal undernutrition is a risk factor for adverse birth outcomes. ${ }^{10}$
Correspondence: Sagni Girma Fage School of Nursing and Midwifery, College of Health and Medical Sciences, Haramaya University, Harar, Ethiopia Email giruu06@gmail.com

International Journal of Women's Health 2021:13 73-79 
Africa has significantly higher undernutrition in pregnancy, ${ }^{8,11}$ and sub-Saharan Africa is the most affected region. ${ }^{11}$ Maternal malnutrition in Ethiopia is higher than many other African countries. ${ }^{9}$ In rural Ethiopia, nearly one in five pregnant women is malnourished. ${ }^{12}$ Chronic energy deficiency is $30.5 \%$ and $26.9 \%$ among nonpregnant and nonpostpartum women, respectively. ${ }^{13}$ Similarly, prevalence of 27\% (Ethiopia Demographic and Health Survey, 2011) indicates that the problem remains unchanged. ${ }^{14}$ In addition, rural women are about $68 \%$ more likely to be malnourished than urban women. ${ }^{9}$

In rural communities, where women play pivotal roles as livestock herder, natural-resource manager, income generator, and service provider - which are highly influenced by gender norms, values, and relationships - they have limited access to health care, education, nutrition, family planning, and reproductive health. ${ }^{15}$ As such, maternal undernutrition, especially in pregnant women, is a major public health issue. Data on the nutritional status of pregnant women in rural communities are scarce in Ethiopia in general and southern Ethiopia in particular. The aim of this study was to assess the prevalence of undernutrition and its associated factors among pregnant women in rural communities in southern Ethiopia.

\section{Methods}

\section{Study Setting}

The study was conducted in Goro Dola District, Guji Zone, Oromia Regional State, southern Ethiopia from June 15 to 30,2020 . The district is located $595 \mathrm{~km}$ to the south of Addis Ababa. It has three urban and 18 rural rural kebeles (the smallest administrative unit in Ethiopia), and an estimated population of 83,243 , of which 2,889 were pregnant. A majority of the residents are sedentary farmers, whose basic livelihood is livestock.

\section{Study Design and Population}

This was a community-based cross-sectional study. All pregnant women in any trimester residing in the district were the source population, while all pregnant women in any trimester who were registered on pregnancy screening-registration books of the health posts in the selected kebeles of the district during the study period were the study population.

\section{Sample Size and Sampling Procedure}

The primary outcome of the study was to identify the prevalence of undernutrition and factors associated with it. The sample size was calculated by using a single population-proportion formula with assumptions of undernutrition prevalence among pregnant women of $31.8 \%$ from a previous study in the Ethiopian Central Rift Valley, ${ }^{16} 5 \%$ margin of error, $95 \%$ confidence level, and $15 \%$ nonresponse rate. As such, the sample size calculated was 383 .

After stratifying kebeles in the district into urban $(n=3)$ and rural $(n=18)$, we allocated the sample size proportionally (proportional to the number of pregnant women in each kebele) to each stratum. The identity of each woman was obtained from the pregnancy screening-registration book of health posts and was used as a sampling frame. Women were then selected by simple random sampling using computer-generated random numbers.

\section{Data Collection Procedure}

Data were collected through face-to-face interviews and anthropometric measurements by going from home to home. Data on sociodemographic, reproductive, medical, behavioral, and health-care factors were collected using a structured questionnaire developed from the literature. ${ }^{17-19}$ Data on minimum dietary diversity for women (MDDW) were collected using the standard FAO 2016 tool. ${ }^{20}$ The MDDW is a composite indicator used to reflect dietary micronutrient adequacy. It is computed using ten food groups (grains, white roots, tubers and plantains, other vegetables, dairy foods, pulses, dark-green leafy vegetables, other vitamin A-rich fruit and vegetables, eggs, other fruit, meat, poultry, and fish, nuts, and seeds) for comparison. Household food insecurity was assessed with the standard Food and Nutrition Technical Assistance 2007 tool. ${ }^{21} \mathrm{Mid}-$ upper arm circumference (MUAC) was measured on women's nondominant hand (arm) at the midpoint between the olecranon process and acromion process.Unstretchable MUAC tape with the correct tension (not too loose/tight) was used, and values were recorded to the nearest $0.1 \mathrm{~cm}$. We took measurements twice, and average values were used for analysis. Eight nurses collected the data, and four health officers supervised the field data-collection process.

The questionnaire was prepared in English and translated into the local language (Afaan Oromoo), then translated back to English by two experts with good command of both languages. Two days' training was given to data collectors and field supervisors on the objectives of the study, contents of the questionnaire, interview techniques, and confidentiality and rights of respondents. To minimize intra- and interobserver variability in measurements, relative technical error of measurement was calculated during the 
training among ten pregnant women. In addition, a pretest was conducted on 19 pregnant women residing in the kebeles of a nearby district. The data-collection process was supervised by SZ and field supervisors.

\section{Data Processing and Analysis}

Data were cleaned, coded, and entered into EpiData 3.1, then exported to SPSS 20 for analysis. The outcome variable, undernutrition, was categorized and coded as 1 for "yes" if MUAC were $<23 \mathrm{~cm}$ and 0 for "no" for MUAC $\geq 23 \mathrm{~cm}$. Descriptive analysis - simple frequencies, means, and ranges - were calculated and presented in the form of statements and tables. A household wealth index was constructed using principal-component analysis by considering locally available household assets and then categorizing as poor, medium, and rich.

A household food-insecurity access score was calculated for each household by summing up the frequency of occurrence of the nine food insecurity-related conditions thatmeasure household food insecurity in the previous 4 weeks. The nine items were recorded as 0 for "no" to each occurrence and 1 for "yes" responses. It was then categorized as food-secure when all items had been answered "no" and food in-secure otherwise.

MDDW, a dichotomous indicator of whether or not the women had eaten five or more of ten food groups in the last 24 hours, was categorized as "MDDW not met" if fewer than five and "MDDW met" otherwise.

Bivariate analyses were done to assess the association between each independent variable and the outcome variable with CORs and 95\% CIs. Then, variables with $p<0.25$ were considered as candidates for the multivariate model. Multicollinearity among the independent variables was checked using the variance-inflation factor. Model fitness was checked with Hosmer-Lemeshow goodness-of-fit test. AORs and 95\% CI were used to estimate strength of association. Statistical significance was set at $p<0.05$.

\section{Results}

\section{Sociodemographic Characteristics}

Of 383 women approached, 376 (98.2\%) participated in the study. Five $(1.3 \%)$ refused any participation, and two $(0.5 \%)$ were not found at home on repeated visits during the fieldwork. A majority of the participants were rural residents $(84.3 \%)$, married $(99.7 \%)$, from the Oromo ethnic group (97.1\%), and Muslim (65.2\%; Table 1).
Table I Sociodemographic Characteristics of Pregnant Women in Rural Communities in Southern Ethiopia, $2020(n=376)$

\begin{tabular}{|l|l|l|l|}
\hline Variables & Category & $\mathbf{n}$ & $\%$ \\
\hline Residence & Rural & 317 & 84.3 \\
& Urban & 59 & 15.7 \\
\hline Age, years & $15-24$ & 221 & 58.8 \\
& $25-34$ & 131 & 34.8 \\
& $35-44$ & 24 & 6.4 \\
\hline Religion & Muslim & 245 & 65.2 \\
& Orthodox & 2 & 0.5 \\
& Protestant & 129 & 34.3 \\
\hline Ethnicity & Oromo & 365 & 97.1 \\
& Others* & 11 & 2.9 \\
\hline Marital & Married & 375 & 99.7 \\
status & Widowed & 1 & 0.3 \\
\hline Education & Unable to read or write & 205 & 54.5 \\
& Able to read and write (but no & 9 & 2.4 \\
& schooling) & 125 & 33.2 \\
& Primary school & 30 & 8 \\
& Secondary school & 7 & 1.9 \\
\hline Wamily size & College and above & 171 & 45.5 \\
& $<5$ & 205 & 54.5 \\
\hline \multirow{2}{*}{ index } & Poor & 335 & 89.1 \\
& Medium & 83 & 8.8 \\
& Rich & 2.1 \\
\hline
\end{tabular}

Note: *Amhara, Gurage and Tigre

\section{Reproductive and Behavioral Characteristics}

In sum, 295 (78.5\%) participants had had their first pregnancy in their teenage, and $10.6 \%$ had a history of abortion. More than half $(57.4 \%)$ reported their pregnancy as unintended, and 100 (26.6\%) reported an illness during their current pregnancy. A total of 26 (6.9\%) women reported domestic violence in the current pregnancy. Although $78.2 \%$ of the women had at least one antenatal care (ANC) visit, only $27.4 \%$ had received prenatal dietary counseling, while almost half (52.1\%) had received iron and folic acid supplementation (Table 2).

\section{Dietary Characteristics}

Although 231 (61.4\%) of the participants were from foodsecure households, a majority (94.1\%) did not met the MDDW (Table 3). Of the ten food groups, dairy products were the most widely consumed $(95.2 \%)$, while fruit and vegetables were the least consumed (4\%). 
Table 2 Reproductive, Health, Environmental, and Behavioral Characteristics of Pregnant Women in rural Communities in Southern Ethiopia, $2020(n=376)$

\begin{tabular}{|c|c|c|c|}
\hline Variables & Category & $\mathbf{n}$ & $\%$ \\
\hline \multirow[t]{2}{*}{ Age at first pregnancy, years } & $<20$ & 295 & 78.5 \\
\hline & $\geq 20$ & 81 & 21.5 \\
\hline \multirow[t]{3}{*}{ Parity (number of live births) } & $>3$ & 128 & 34.0 \\
\hline & $1-3$ & 156 & 41.5 \\
\hline & 0 & 92 & 24.5 \\
\hline \multirow[t]{3}{*}{ Gravidity (number of pregnancy) } & $\geq 5$ & 130 & 34.6 \\
\hline & $3-4$ & 108 & 28.7 \\
\hline & $\leq 2$ & 138 & 36.7 \\
\hline \multirow[t]{2}{*}{ History of abortion } & Yes & 40 & 10.6 \\
\hline & No & 336 & 89.4 \\
\hline \multirow[t]{2}{*}{ GA, weeks } & $\leq 28$ & 214 & 56.9 \\
\hline & $>28$ & 162 & 43.1 \\
\hline \multirow[t]{2}{*}{ Pregnancy intention } & Unintended & 216 & 57.4 \\
\hline & Intended & 160 & 42.6 \\
\hline \multirow[t]{2}{*}{ ANC visits } & No & 82 & 21.8 \\
\hline & Yes & 294 & 78.2 \\
\hline \multirow[t]{2}{*}{ Illness during current pregnancy } & Yes & 100 & 26.6 \\
\hline & No & 276 & 73.4 \\
\hline \multirow[t]{2}{*}{ IFA supplementation } & No & 196 & 52.1 \\
\hline & Yes & 180 & 47.9 \\
\hline \multirow[t]{2}{*}{ Prenatal dietary counseling } & No & 273 & 72.6 \\
\hline & Yes & 103 & 27.4 \\
\hline \multirow{2}{*}{$\begin{array}{l}\text { Participating in Women's HDA } \\
\text { meetings }\end{array}$} & Yes & 342 & 91.0 \\
\hline & No & 34 & 9.0 \\
\hline \multirow[t]{2}{*}{ Latrine possession } & No & 54 & 14.4 \\
\hline & Yes & 322 & 85.6 \\
\hline \multirow[t]{2}{*}{ Drinking-water source } & Unprotected & 271 & 72.1 \\
\hline & Protected & 105 & 27.9 \\
\hline \multirow[t]{2}{*}{ ITN possession } & Yes & 287 & 76.3 \\
\hline & No & 89 & 23.7 \\
\hline
\end{tabular}

Abbreviations: ANC, antenatal care; GA, gestational age; IFA, iron and folic acid; HAD, Health Development Army; ITN, insecticide-treated net.

\section{Undernutrition and Its Associated Factors}

The overall prevalence of undernutrition (MUAC $<23 \mathrm{~cm})$ in our study was $41.2 \%(95 \%$ CI $36.3 \%-$ 46.3\%). Age at first pregnancy, pregnancy intention, household food-security status, participating in Wome's Health Development Army meetings, ANC visits, and MDDW were independently associated with undernutrition. In addition, illness during current pregnancy,
Table 3 Dietary Characteristics of Pregnant Women in Rural Communities in Southern Ethiopia, $2020(n=376)$

\begin{tabular}{|l|l|l|l|}
\hline Variables & Category & $\mathbf{n}$ & $\%$ \\
\hline MDDW & $<5$ & 354 & 94.1 \\
& $\geq 5$ & 22 & 5.9 \\
\hline Household food-security status & Food in-secure & 145 & 38.6 \\
& Food secure & 231 & 61.4 \\
\hline Dining time at home & Last (after family & 177 & 47.1 \\
& eat) & & \\
& With family & 173 & 46.0 \\
& First (before & 26 & 6.9 \\
\hline family) & & \\
\hline Ever skipping meals during this & Yes & 113 & 30.1 \\
& No & 263 & 69.9 \\
\hline Food aversion & Yes & 78 & 20.7 \\
& No & 298 & 79.3 \\
\hline
\end{tabular}

Abbreviation: MDDW, minimum dietary diversity for women.

insecticide-treated net (ITN) possession, and gravidity were also included in the model, but not significantly associated with undernutrition.

Women with unintended pregnancies were 2.06 times (AOR 2.06, 95\% CI 1.27-3.36) more likely to be undernourished than their counterparts. Women not participating in Health Development Army meetings were 3.64 times (AOR 3.64, 95\% CI 1.51-8.77) more likely to develop undernutrition than their counterparts participating in such meetings. Pregnant women with MDDW fewer than five food groups were $76 \%$ (AOR $0.24,95 \%$ CI $0.07-0.82$ ) less likely to develop undernutrition. In addition, the odds of developing undernutrition was decreased by $54 \%$ (AOR $0.46,95 \%$ CI $0.27-0.78$ ) for pregnant women who had at least one ANC visit compared to those with no ANC visits. The likelihood of undernutrition was $61 \%$ (AOR $0.39,95 \%$ CI $0.21-0.76$ ) and $74 \%$ (AOR $0.26,95 \%$ CI $0.16-0.43)$ less likely among women whose age at first pregnancy was $\geq 20$ years and living in food-secure households, respectively, than their counterparts (Table 4).

\section{Discussion}

This study assessed nutritional status of pregnant women living in Goro Dola District, a primarily rural community. We found that about four in ten women in our study were undernourished. Age at first pregnancy, pregnancy intention, household food-security status, participating in Health Development Army meetings, ANC visits, and MDDW were independent predictors of undernutrition. 
Table 4 Factors Associated with Undernutrition among Pregnant Women in Rural Communities in Southern Ethiopia, 2020 ( $n=376$ )

\begin{tabular}{|c|c|c|c|c|c|}
\hline \multirow[t]{3}{*}{ Variables } & \multirow[t]{3}{*}{ Category } & \multicolumn{2}{|c|}{ Undernutrition } & \multirow[t]{3}{*}{ COR $(95 \% \mathrm{CI})$} & \multirow[t]{3}{*}{ AOR (95\% Cl) } \\
\hline & & Yes & No & & \\
\hline & & n (\%) & n (\%) & & \\
\hline Age at first pregnancy, years & $\begin{array}{l}\geq 20 \\
<20\end{array}$ & $\begin{array}{l}17(21) \\
138(46.8)\end{array}$ & $\begin{array}{l}64(79) \\
157(53.2)\end{array}$ & $\begin{array}{l}0.30(0.17-0.54) \\
\mathrm{I}\end{array}$ & $\begin{array}{l}0.39(0.21-0.76)^{*} \\
\text { I }\end{array}$ \\
\hline Pregnancy intention & $\begin{array}{l}\text { Unintended } \\
\text { Intended }\end{array}$ & $\begin{array}{l}104(48) \\
51(31.8)\end{array}$ & $\begin{array}{l}112(52) \\
109(68.2)\end{array}$ & $\begin{array}{l}1.98(1.29-3.04) \\
1\end{array}$ & $2.06(1.27-3.36)^{*}$ \\
\hline Illness during current pregnancy & $\begin{array}{l}\text { No } \\
\text { Yes }\end{array}$ & $\begin{array}{l}99(35.8) \\
56(56)\end{array}$ & $\begin{array}{l}\text { I77 (64.2) } \\
44(44)\end{array}$ & $\begin{array}{l}0.44(0.28-0.70) \\
\text { I }\end{array}$ & $\begin{array}{l}0.58(0.33-1.02) \\
1\end{array}$ \\
\hline Household food-security status & $\begin{array}{l}\text { Food secure } \\
\text { Food in-secure }\end{array}$ & $\begin{array}{l}66(28.5) \\
89(61.4)\end{array}$ & $\begin{array}{l}165(71.5) \\
56(38.6)\end{array}$ & $\begin{array}{l}0.25(0.16-0.39) \\
I\end{array}$ & $\begin{array}{l}0.26(0.16-0.43) * * \\
1\end{array}$ \\
\hline ITN possession & $\begin{array}{l}\text { No } \\
\text { Yes }\end{array}$ & $\begin{array}{l}46(51.7) \\
109(38)\end{array}$ & $\begin{array}{l}43(48.3) \\
178(62)\end{array}$ & $\begin{array}{l}1.75(1.08-2.82) \\
\mathrm{I}\end{array}$ & $\begin{array}{l}1.26(0.69-2.28) \\
\text { I }\end{array}$ \\
\hline Participating in HDA meetings & $\begin{array}{l}\text { No } \\
\text { Yes }\end{array}$ & $\begin{array}{l}23(67.6) \\
132(38.6)\end{array}$ & $\begin{array}{l}11(32.4) \\
210(61.4)\end{array}$ & $\begin{array}{l}3.33(1.57-7.05) \\
\mathrm{I}\end{array}$ & $\begin{array}{l}3.64(I .5 \mathrm{I}-8.77)^{*} \\
\mathrm{I}\end{array}$ \\
\hline ANC visits & $\begin{array}{l}\text { Yes } \\
\text { No }\end{array}$ & $\begin{array}{l}99(36.3) \\
56(54.4)\end{array}$ & $\begin{array}{l}\text { I74 (63.7) } \\
47(45.6)\end{array}$ & $\begin{array}{l}0.48(0.30-0.76) \\
\text { I }\end{array}$ & $\begin{array}{l}0.46(0.27-0.78) * \\
\text { I }\end{array}$ \\
\hline MDDW & $\begin{array}{l}\geq 5 \\
<5\end{array}$ & $\begin{array}{l}4(18.2) \\
15 \mid(42.6)\end{array}$ & $\begin{array}{l}18(81.8) \\
203(57.4)\end{array}$ & $\begin{array}{l}0.29(0.05-0.76) \\
I\end{array}$ & $\begin{array}{l}0.24(0.07-0.82)^{*} \\
\mathrm{I}\end{array}$ \\
\hline Gravidity & $\begin{array}{l}\geq 5 \\
3-4 \\
\leq 2\end{array}$ & $\begin{array}{l}53(40.8) \\
55(51) \\
47(34)\end{array}$ & $\begin{array}{l}77(59.2) \\
53(49) \\
91(66)\end{array}$ & $\begin{array}{l}\text { I } \\
0.75(0.46-1.23) \\
0.49(0.29-0.83)\end{array}$ & $\begin{array}{l}\text { I } \\
0.91(0.47-1.75) \\
0.52(0.27-1.01)\end{array}$ \\
\hline
\end{tabular}

Notes: ${ }^{*}<0.05 ; * *<0.001$. COR from bivariate model and AOR from multivariate model.

Abbreviations: MDDW, minimum dietary diversity for women; ITN, insecticide-treated net; HDA, Health Development Army.

Our finding of undernutrition (41.2\%) was consistent with previous studies conducted in the Ethiopian Central Rift Valley and western Ethiopia. ${ }^{16,19}$ However, it was higher than reports from studies conducted in eastern Ethiopia, ${ }^{12}$ northern Ethiopia, ${ }^{22}$ Shashemene, ${ }^{23}$ and Hosanna. ${ }^{15}$ This difference might be due to seasonal variations and socioeconomic conditions. Since our study was conducted during a known hunger season, this might have contributed to the higher undernutrition in the current study. The effect of seasonal variation on nutritional status has been previously reported in Ethiopia. ${ }^{24}$

In agreement with previous studies conducted in Ethiopia, pregnant women whose age at first pregnancy was $\geq 20$ years were less likely to be undernourished. ${ }^{23,25}$ Age is believed to exert an impact on their health and thereby nutritional status during pregnancy, since it provides time to complete maternal growth before starting to invest in fetal growth. ${ }^{5}$ In addition, women who had at least one ANC visit were less likely to be undernourished, which is in line with a previous study in Shashemene district,
Ethiopia. ${ }^{23}$ This might be because those who visit health institutions were getting health and nutrition education, as well as advice, from health professionals. Furthermore, women who had an MDDW fewer than five foog groups were less likely to be undernourished. This is similar to other studies in Ethiopia. ${ }^{15,26}$ This could be due to the fact that consumption of diversified foods helps women to get better-quality foods that enhance their immunity and thus improve their nutritional status. ${ }^{27,28}$ Women from foodsecure households were less likely to be undernourished, and it is similar to findings previously reported in southern ${ }^{29}$ and eastern Ethiopia. ${ }^{30}$ This could be because food insecurity affects the quality of the diet. ${ }^{31,32}$

Women with unintended pregnancies were more likely to be undernourished. This finding is similar to evidence from low- and middle-income countries indicating that unwanted pregnancies can affect maternal nutrition, health service, and child nutrition. ${ }^{22,33}$ This could be associated with women's demand to invest in their pregnancy or spouse support as a result of their planned pregnancy. 
We were surprised that women who did not participate in Women's Health Development Army meetings were more likely to be undernourished than their counterparts. This could be related to discussion about nutrition in pregnancy among meeting participants in such meetings. The importance of such informal women's groups in decreasing maternal death and improving maternal and child healthservice utilization has been previously reported. ${ }^{34}$

Major strengths of this study were using the community-based approach and the random selection of study participants. The use of an established pregnancyregistration book for the sampling frame makes our study more representative of the district. We also used standardized tools and procedures for dietary diversity, food insecurity, and anthropometric assessments. However, this study could not establish a temporal relationship between undernutrition and its predictors, since its design was cross-sectional. Underreporting by women about their diet might also have occurred during interviews.

\section{Conclusion}

Undernutrition among pregnant women was highly prevalent in the study area. Interventions aiming to reduce undernutrition should focus on discouraging teenage and unintended pregnancy, reducing household food insecurity, promoting ANC utilization, and consumption of diversified diets by women. Strengthening the existing network of the Wome's Health Development Army could be important in the fight against undernutrition in pregnant women in such communities or beyond.

\section{Ethics Approval and Informed Consent}

Ethics clearance was obtained from the Institutional Health Research Ethics Review Committee (IHRERC) of the College of Health and Medical Sciences, Haramaya University (IHRERC/121/2020). Then, an official letter was submitted to Goro Dola District Health Office. Formal letters of cooperation were sent to all concerned bodies. Informed, voluntary, written, and signed consent was sought from women aged $\geq 18$ years. For those aged $<18$ years, parental informed consent was obtained as per the approval by the ethical review committee. Each study participant was informed that she was being contacted for research purposes and approached after informed consent was obtained. Confidentiality of information was ensured by anonymous data collection using codes only. The collected data were kept in a protected drawer and accessed only by SZ. Women with undernutrition were referred to appropriate nearby facilities. This study was conducted in accordance with the Declaration of Helsinki.

\section{Acknowledgments}

The authors are very much thankful to Goro Dola District Health Office, study participants, data collectors, and field supervisors.

\section{Author Contributions}

All authors made substantial contributions to conception and design, acquisition of data, or analysis and interpretation of data, took part in drafting the article or revising it critically for important intellectual content, agreed to submit to the current journal, gave final approval to the version to be published, and agree to be accountable for all aspects of the work.

\section{Funding}

The authors did not receive any funding for this study. All costs were covered by the authors.

\section{Disclosure}

The authors report no conflicts of interest in this work.

\section{References}

1. Stratton RJ, Green CJ, Elia M. Disease-Related Malnutrition: An Evidence-Based Approach to Treatment. CABI Publishing; 2003. Available from https://scholar.google.com/scholar?hl=en $\approx \mathrm{sdt}=0 \%$ 2C5\&q=info\%3A_RQqkbVI89UJ\%3 Ascholar.google.com\% $2 \mathrm{~F} \& \mathrm{btnG}=$. Accessed: August 15, 2020.

2. Kramer CV, Allen S. Malnutrition in developing countries. Paediatr Child Health. 2015;25(9):422-427. doi:10.1016/j.paed.2015.04.002

3. Meier R, Stratton R. Basic concepts in nutrition: epidemiology of malnutrition. E Spen Eur E J Clin Nutr Metab. 2008;4(3):e167-e170. doi:10.1016/j.eclnm.2008.04.002

4. Ahmed T, Haque R, Shamsir Ahmed AM, Petri Jr JWA, Cravioto A. Use of metagenomics to understand the genetic basis of malnutrition. Nutr Rev. 2009;67(suppl_2):S201-S206. doi:10.1111/j.17534887.2009.00241.x

5. Bhutta ZA, Ahmed T, Black RE, et al. What works? Interventions for maternal and child undernutrition and survival. The Lancet. 2008;371 (9610):417-440. doi:10.1016/S0140-6736(07)61693-6

6. Bhutta ZA, Das JK, Rizvi A, et al. Evidence-based interventions for improvement of maternal and child nutrition: what can be done and at what cost? The Lancet. 2013;382(9890):452-477. doi:10.1016/S01406736(13)60996-4

7. Black RE, Allen LH, Bhutta ZA, et al. Maternal and child undernutrition: global and regional exposures and health consequences. The Lancet. 2008;371(9608):p. 243-260. doi:10.1016/S0140-6736(07) 61690-0 
8. Lartey A. Maternal and child nutrition in Sub-Saharan Africa: challenges and interventions. Proc Nutri Soc. 2008;67(1):p. 105-108. doi: $10.1017 / \mathrm{S} 0029665108006083$

9. Uthman O, Aremu O. Malnutrition among women in sub-Saharan Africa: rural-urban disparity. 2008.

10. Rahma MS, Howlader T, Masud MS, Rahman ML. Association of low-birth weight with malnutrition in children under five years in Bangladesh: do mother's education, socio-economic status, and birth interval matter? PLoS One. 2016;11(6):p. e0157814. doi:10.1371/ journal.pone. 0157814

11. Adebowale SA, Adepoju OT, Okareh TO, Fagbamigbe FA. Social epidemiology of adverse nutritional status outcomes among women in Nigeria: NDHS, 2008. Pak J Nutr. 2011;10(9):p. 888-98. doi:10.3923/pjn.2011.888.898

12. Kedir H, Berhane Y, Worku A. Magnitude and determinants of malnutrition among pregnant women in eastern Ethiopia: evidence from rural, community-based setting. Matern Child Nutr. 2016;12(1) p. $51-63$. doi: $10.1111 / \mathrm{mcn} .12136$

13. Bitew F, Telake DS. Undernutrition among women in Ethiopia: ruralurban disparity. DHS working papers No. 77; 2010.

14. CSA-Ethiopia, I.C.F. International. Ethiopia Demographic and Health Survey 2011. Central Statistical Agency of Ethiopia and ICF International Addis Ababa, Ethiopia and Calverton. Maryland, USA; 2012.

15. Tadesse A, Hailu D, Bosha T. Nutritional status and associated factors among pastoralist children aged 6-23 months in Benna Tsemay Woreda, South Omo zone, Southern Ethiopia. Int J Nutri Food Sci. 2018;7(1):p. 11-23. doi:10.11648/j.ijnfs.20180701.13

16. Mariyam AF, Dibaba B. Epidemiology of malnutrition among pregnant women and associated factors in central refit valley of Ethiopia, 2016. J Nutr Disord Ther. 2018;8(01):p. 1-8. doi:10.4172/21610509.1000222

17. Ververs MT, Antierens A, Sackl A, Staderini N, Captier V. Which anthropometric indicators identify a pregnant woman as acutely malnourished and predict adverse birth outcomes in the humanitarian context? PLoS Curr. 2013;5.

18. Nigatu M, Gebrehiwot TT, Gemeda DH. Household food insecurity, low dietary diversity, and early marriage were predictors for Undernutrition among pregnant women residing in Gambella, Ethiopia. Advan Public Health. 2018;2018:1-10. doi:10.1155/2018/ 1350195

19. Shiferaw A, Husein G. Acute under nutrition and associated factors among pregnant women in Gumay District, Jimma Zone, South West Ethiopia. J Women's Health Care. 2019;8(459):2167-0420.1000459.

20. FAO F. Minimum Dietary Diversity for Women: A Guide for Measurement. Rome: FAO; 2016:82.

21. Coates J, Swindale A, Bilinsky P. Household Food Insecurity Access Scale (HFIAS) for Measurement of Food Access: Indicator Guide: Version 3. 2007.
22. Gebre B, Biadgilign S, Taddese Z, Legesse $T$, Letebo $M$. Determinants of malnutrition among pregnant and lactating women under humanitarian setting in Ethiopia. BMC Nutri. 2018;4(1):p. 11. doi:10.1186/s40795-018-0222-2

23. Belete Y, Negga B, Firehiwot M. Undernutrition and associated factors among adolescent pregnant women in Shashemenne District, West Arsi Zone, Ethiopia: a communitybased study. J Nutr Food Sci. 2016;6(1):p. 1-7.

24. Roba KT, O’Connor TP, Belachew T, O’Brien NM. Seasonal variation in nutritional status and anemia among lactating mothers in two agro-ecological zones of rural Ethiopia: a longitudinal study. Nutrition. 2015;31(10):p. 1213-1218. doi:10.1016/j.nut.2015.03.007

25. Dadi AF, Desyibelew HD. Undernutrition and its associated factors among pregnant mothers in Gondar town, Northwest Ethiopia. PLoS One. 2019;14(4):p. e0215305. doi:10.1371/journal.pone.0215305

26. Workicho A, Belachew T, Feyissa GT, et al. Household dietary diversity and Animal Source Food consumption in Ethiopia: evidence from the 2011 Welfare Monitoring Survey. BMC Public Health. 2016;16(1):p. 1192. doi:10.1186/s12889-016-3861-8

27. Darnton-Hill I, Mkparu UC. Micronutrients in pregnancy in low- and middle-income countries. Nutrients. 2015;7:p. 1744-1768. doi:10.3390/nu7031744

28. Lee SE, Talegawkar SA, Merialdi M, Caulfield LE. Dietary intakes of women during pregnancy in low- and middle-income countries. Public Health Nutr. 2012;16(8):p. 1340-1353. doi:10.1017/ S1368980012004417

29. Kuche D, Singh P, Moges D, Belachew T. Nutritional status and associated factors among pregnant women in Wondo Genet District, Southern Ethiopia. J Food Sci Eng. 2015;5(2):p. 85-94.

30. Awel AA, Lema TB, Hebo HJ. Nutritional status and associated factors among primary school adolescents of pastoral and agro-pastoral communities, Mieso Woreda, Somali Region, Ethiopia: a comparative cross-sectional study. J Public Health Epidemiol. 2016;8(11):p. 297-310.

31. Kim HJ, Oh K. Household food insecurity and dietary intake in Korea: results from the 2012 Korea National Health and Nutrition Examination Survey. Public Health Nutr. 2015;18(18):p. 3317-25. doi:10.1017/S1368980015000725

32. Hanson KL, Connor LM. Food insecurity and dietary quality in US adults and children: a systematic review. Am J Clin Nutr. 2014;100 (2):p. 684-92. doi:10.3945/ajcn.114.084525

33. Hajizadeh M, Nghiem S. Does unwanted pregnancy lead to adverse health and healthcare utilization for mother and child? Evidence from low-and middle-income countries. Int J Public Health. 2020;65 (4):457-468. doi:10.1007/s00038-020-01358-7

34. Yitbarek K, Abraham G, Morankar S. Contribution of women's development army to maternal and child health in Ethiopia a systematic review of evidence. BMJ Open. 2019;9(5):p. e025937.

International Journal of Women's Health

Dovepress

\section{Publish your work in this journal}

The International Journal of Women's Health is an international, peerreviewed open-access journal publishing original research, reports, editorials, reviews and commentaries on all aspects of women's healthcare including gynecology, obstetrics, and breast cancer. The manuscript management system is completely online and includes a very quick and fair peer-review system, which is all easy to use Visit http://www.dovepress.com/testimonials.php to read real quotes from published authors. 